extract and carry with them. Toward that end, Table 1 summarizes our advice for developing high-quality clinical reviews.

We look forward to a journal that brings to its readers-clinicians and researchers alike-clinical reviews of the highest quality, reviews that will set standards for evidence-based primary care. At the same time, we appreciate that such reviews are not easily developed, and that many of our prospective clinical review authors may be inexperienced with the approach we describe. But we view this as a joint venture, with authors and editors working together to enhance the quality of JGIM's clinical reviews. The Journal is most assuredly up for re- view(s). - JACK ENDE, MD, Division of General Internal Medicine, Hospital of the University of Pennsylvania, Philadelphia, PA 19104-4283; and Cynthia D. Mulrow, MD, Ambulatory Care, Audie L. Murphy Memorial Veterans Hospital, San Antonio, TX

\section{REFERENCES}

1. Oxman AD. Checklists for review articles. BMJ. 1994;309:648-51.

2. Mulrow $\mathrm{CD}$. The medical review article: state of the science. Ann Intern Med. 1987;106:485-8.

3. Haynes RB, Mulrow CD, Huth EJ. Altman DG, Gardner MJ. More informative abstracts revisited. Ann Intern Med. 1990;113:69-76.

\title{
Quality of AIDS Care in a Changing Health Care System
}

$\mathbf{T}$ o date, few studies have been published that shed light on how well people with HIV-related illnesses fare in different kinds of care organizations and with different constellations of providers. In the issue of the Journal, Stone and colleagues,' using data from the Boston Health Study, explore correlates of satisfaction with ambulatory care for persons with AIDS. They provide one of the first comparisons of AIDS patients' perceptions of care in three organizationally distinct service settings: a public-hospital HIV clinic, a teaching-hospital group medical practice, and a staff-model health maintenance organization (HMO). Patients receiving their care at the public-hospital HIV clinic staffed by faculty attending physicians were significantly more likely than were those at the other two sites to rate the quality of care low. Perceptions of care among those AIDS patients treated at the HMO were comparable to those of the patients attending a general internal medicine group practice at a teaching hospital. These findings, if substantiated by subsequent research, are encouraging in view of the rapid growth of HMOs. There is no evidence from this study that people with AIDS treated in a staff-model HMO perceive their care to be of low quality. Indeed, the findings suggest that shifting AIDS patients out of hospital-based clinics and into HMOs might actually improve care.

The major finding of this study is that the patients who identified a primary nurse reported significantly higher quality of care scores than did the other patients. Moreover, the presence of an identifiable primary nurse was strongly predictive of greater patient satisfaction, independent of site of care. This is an important finding because surprisingly little research has focused on the contributions of nurses to AIDS care, despite their centrality in the provision of services. Prominent AIDS phy- sicians, in a national survey of what makes a great hospital, ranked nursing as the single most important component in an excellent inpatient AIDS service. ${ }^{2}$ In a single-site pilot study conducted in a teaching-hospital HIV clinic, we compared outcomes for ambulatory patients with HIV-related illnesses whose primary providers were nurse practitioners vs physicians. ${ }^{3}$ The patients of nurse practitioners reported significantly fewer problems with their care, and their functional levels were comparable to those of the physician-treated patients, even though the nurses patients were more severely ill on average.

There is a large research literature documenting the success of nurses in improving patient satisfaction, enhancing function, and reducing inappropriate utilization of emergency and inpatient services for persons with a wide range of chronic illnesses. ${ }^{4.5}$ Their success appears to be related to the centrality of caring (as compared to curing) to nurses and the nursing profession, and the high priority nurses have traditionally placed on maintenance or restoration of function in everyday living. ${ }^{6}$ Caring for persons with AIDS calls upon the entire range of physical, psychological, and social interventions that nurses are characteristically and, in many respects. singularly educated to provide. While nurses show some of the same fears of occupational transmission of HIV that remain widespread among health care workers, there is increasing evidence that nurses do not perceive caring for AIDS patients as hopeless, a perception that has been widespread among physicians. ${ }^{7}$

Several large-scale studies have interesting findings in this regard. Contrary to popular beliefs, nurses practicing on inpatient AIDS units who spend full time in AIDS care experience less burnout than do nurses practicing on general medical units. ${ }^{8}$ A national study of the 
attitudes of health professionals to AIDS care and people with AIDS found that nurses' attitudes became more favorable the more contact they had with AIDS patients, while physicians' attitudes became more negative with greater contact. ${ }^{9}$ The accumulation of evidence, including the results of the study of ambulatory AIDS care published in this issue, points to the considerable potential of nurses to improve quality of care for people with AIDS in all care settings. AIDS care is beset by a multitude of problems and challenges that will not be easily solved. In that light, creating more central roles for nurses would appear to be a feasible way to have more than a marginal impact on the quality of AIDS care.

The Stone et al. paper also provides sobering confirmation of the nation's continuing problems providing satisfactory health care to African Americans, particularly those from poor, urban areas. The increasing dissemination of HIV infection in poor minority populations will pose perhaps the greatest challenge to the organization of appropriate and satisfactory AIDS care in the future. The present restructuring of the health care marketplace in the absence of universal insurance coverage poses new difficulties for vulnerable populations. Even the Medicare program with its universal insurance coverage has not yet been successful in providing care to inner-city black beneficiaries that is comparable to that received by others. ${ }^{10}$ Financing is part but not all of the problem. This study suggests that organizational models of care patterned more along the lines of private-sector medical group practices or HMOs and including primary nurses offer the possibility of more satisfactory care than has been traditionally available in hospital-based clinics, which have long been the only choice for the inner-city poor.-Linda H. Aiken, PhD, Center for Health Services and Policy Research, School of Nursing, and the Department of Sociology, University of Pennsylvania, Philadelphia, PA 19104-6096

\section{REFERENCES}

1. Stone VE, Weissman JS, Cleary PD. Satisfaction with ambulatory care of persons with AIDS: predictors of patient ratings of quality. J Gen Intern Med. 1995;10:239-45

2. Reputations are made of these. U.S. News World Rep. 1990;Apr 30:83.

3. Aiken LH, Lake ET, Semaan S, et al. Nurse practitioner managed care for persons with HIV infection. Image: J Nurs Scholarship. 1993;25:172-7.

4. Office of Technology Assessment. Nurse Practitioners, Physicians* Assistants and Certified Nurse-Midwives: A Policy Analysis (Health Technology Case Study No. 37). Washington, DC: U.S. Government Printing Office, 1986.

5. Brown SH, Grimes DE. Nurse Practitioners and Certified NurseMidwives: A Meta-Analysis of Studies of Nurses in Primary Care Roles. Washington, DC: American Nurses Foundation, 1993.

6. Fox RC, Aiken LH, Messikomer CM. The culture of caring: AIDS and the nursing profession. Milbank Q. 1990;68(suppl 2):226-56.

7. Cooke M, Sande MA. The HIV epidemic and training in internal medicine. N Engl J Med. 1989;321:1334-8.

8. Aiken LH, Smith HL, Lake ET. Effects of organizational innovations in AIDS care on "burnout" among urban hospital nurses. Cincinnati, OH: presented at the Annual Meeting of the American Sociological Association, 1991.

9. Colombotos J, Messeri P, McConnell MB, Elinson J, Gemson D, Hynes M. Physicians, nurses, and AIDS; findings from a national study. Rockville, MD: Agency for Health Care Policy and Research (publ. no. 93-0043), Aug 1994.

10. Physician Payment Review Commission. Monitoring Access of Medicare Beneficiaries (Report to Congress No. 92-5). 1992.

\section{To Screen or Not to Screen:}

\section{What Is the Question?}

E lsewhere in this issue of the Journal, Brett analyzes current controversies in breast and prostate cancer screening and concludes that we need a single set of national screening recommendations that would be recognized as the "basic" standard of care by patients, physicians, and payers. ${ }^{1}$ He argues that the U.S. Preventive Services Task Force should make these recommendations because this group is relatively free of conflicts of interest and uses conservative, evidence-based decision rules.

Leaving aside the question of how one might vest any group with such supreme authority, Brett's conclusion-based on the criteria of objectivity and methodologic rigor-makes sense only if one believes that these screening controversies are largely over the proper interpretation of imperfect data. Very different conclusions result if one believes, as I do, that the interpretation of the scientific evidence is perhaps the least controversial aspect of these debates. Most, but certainly not all, voices in these debates agree that there is inadequate evidence to support prostate-specific antigen (PSA) screening for most men or mammography for women under the age of 50 years - the controversy is whether to screen in the absence of such evidence. To many thoughtful individuals who disagree with the Task Force recommendations, the lack of such evidence is merely a "type II" error to be corrected by future research and reflects the limitations of older technology and treatments.

My alternative vision of these controversies is that they are mostly fueled by competing beliefs, perspectives, values, and interests. Looked at this way, any proposed solution must provide a way to balance different 